\title{
O COMPROMISSO E DESAFIO DA INSERÇÃO SOCIAL E DA APLICABILIDADE DA PRODUÇÃO INTELECTUAL DOS MESTRADOS PROFISSIONIAS
}

\author{
Fernando Negret Fernandez, Heliane Prudente Nunes, Paulo Cesar Bontempo \\ Mestrado em Desenvolvimento Regional da Faculdades Alves Faria - ALFA, Goiânia-GO
}

\section{Resumo}

A análise das principais Portarias da Capes demonstra que os objetivos essenciais dos mestrados profissionais são a formação teórica e prática dos discentes e a produção acadêmica aplicável, a qual deve ser facilitada pela inserção social e pela atuação coordenada das diferentes instâncias dos cursos. Neste sentido foi analisado o papel das instituições de educação superior, das mantenedoras, da estrutura acadêmica do curso, do corpo docente e discente, para atuar coordenadamente, conseguir resultados e atingir esses objetivos. Estes são os aspectos apresentados e discutidos no decorrer deste artigo.

Palavras Chave: Mestrados Profissionais. Produção Intelectual. Inserção Social. Aplicabilidade.

\begin{abstract}
The analysis of the main rulings of Capes demonstrates that the essential goals of Professional masters degrees courses are the theoretical and practical training of students, and research applicable, which should be facilitated by social and coordinated action of the different instances of the courses. In this regard, we investigated the role of higher education institutions, of the sponsors, the academic structure of the course, the faculty and students, to act coordinately, get results and achieve those goals. These aspects are presented and discussed throughout this article.
\end{abstract}

Keywords: Professional Masters. Intellectual Production. Social Inclusion. Applicability. 


\section{Introdução}

O artigo tem por objetivo apresentar, com base nas normas estabelecidas nas principais Portarias da Capes, as características, os objetivos e os princípios que orientam os mestrados profissionais. Essas Portarias definem desde o início que esta modalidade de mestrados deve ter o mesmo nível de qualidade dos cursos dos mestrados vigentes, que as instituições proponentes devem ter condições suficientes para fazer a gestão adequada destes cursos e estes devem ter uma estrutura acadêmica que permita a formação de profissionais com rigor científico e produção acadêmica aplicável.

Essa aplicabilidade da produção intelectual deve ser facilitada pela ação coordenada das instâncias que participam no desenvolvimento do curso e apoiam a inserção social dos projetos de pesquisa dos professores e dos alunos, em cujo âmbito se gera a produção acadêmica aplicável. O artigo trata do papel de cada instância neste desafio e compromisso da aplicabilidade e da inserção social da produção intelectual.

Além de uma breve menção da Metodologia utilizada e das Considerações Finais, o artigo inclui os resultados em duas partes: inicialmente os comentários sobre o conteúdo das portarias e posteriormente o papel das Instituições de Ensino Superior - IES, das Mantenedoras, da estrutura acadêmica dos cursos e dos corpos docente e discente na gestão do desenvolvimento dos cursos para a geração da produção intelectual aplicável. Assume-se que esta aplicabilidade dos conhecimentos gerados somente será possível mediante a inserção social dos trabalhos dos docentes e discentes.

\section{Metodologia}

O presente artigo foi desenvolvido com base em pesquisa bibliográfica e documental. Foram analisadas as principais Portarias da Capes que definem as características, objetivos e princípios dos mestrados profissionais, bem como consultados livros sobre teoria da educação e da ciência, artigos sobre as instâncias que integram os cursos e documentos institucionais sobre diretrizes que regem esta modalidade de mestrados. É fonte importante deste artigo o Relatório do $2^{\circ}$ Encontro dos Mestrados Profissionais realizado nas Faculdades Alves Faria ALFA, em Goiânia, em 2012.

\section{Resultados}

\subsection{Principais Objetivos e Diretrizes sobre os Mestrados Profissionais contidos nas Portarias e Normas da Capes.}

As Portarias da CAPES sobre os Mestrados Profissionais incorporam normas e diretrizes que expressam com suficiência quais tem sido e são os objetivos e a identidade dos cursos de pós-graduação no Brasil. De fato, as Portarias No 47 de 1995, a No 80 de 1998 e a $\mathrm{N}^{\mathrm{o}} 17$ de 2009, integram um conjunto de princípios, propósitos e diretrizes, com base nos quais estão estabelecidas as características e as bases de orientação dos Mestrados Profissionais.

A Primeira Portaria referente aos mestrados profissionais é a $\mathrm{N}^{\circ} 47$ de 1995, a qual estabelece no âmbito da Capes, a implantação de procedimentos para "a recomendação, acompanhamento e avaliação de cursos de mestrado orientados a formação profissional", com o fim de "assegurar níveis de qualidade comparáveis aos vigentes no sistema de pósgraduação”. (Revista Brasileira de Pós-Graduação - RBPG 147-148, 2005). Cabe destacar então que desde o inicio as diretrizes para os mestrados profissionais foram manter a mesma qualidade dos cursos do sistema de pós-graduação vigentes. 
A mesma Portaria $N^{\circ} 47$ estabelece nos seus diferentes artigos, entre outros aspectos, que a instituição proponente deve demonstrar condições para o desenvolvimento e perspectivas adequadas do curso e que os docentes e orientadores devem ser doutores de qualificação inquestionável e produção intelectual de alto nível.

Com relação às atividades do ensino, ficou estabelecido que o curso deverá articulá-las com as aplicações de pesquisa, com projetos em parceria com o setor produtivo e de extensão, orientando e assegurando desse modo e desde o início, que a aplicabilidade é o principio essencial da produção nos mestrados profissionais. Igualmente esta Portaria determinou como tempo mínimo de titulação 1 ano e estabeleceu que "o estudante deve apresentar trabalho final que demonstre domínio do objeto de estudo e capacidade de expressar-se sobre ele", o qual poderá tomar formas, entre outras, de "dissertação, projeto, análise de casos, performance, produção artística, desenvolvimento de instrumentos, equipamentos e protótipos”. (RBPG, 147-148, 2005).

Cabe ser ressaltado que desde essa Portaria inicial de 1995, já se pensava que o trabalho final do estudante dos mestrados profissionais poderia ter diversas formas de apresentação, o qual tem sido ainda objeto de discussão. A polêmica foi aquecida pela Portaria 17 de 2009 que ampliou consideravelmente o tipo de modalidades que podem ser entregues como trabalhos finais de mestrado, algum deles questionados na sua relevância e se realmente seu nível de exigência é congruente com um curso de mestrado.

A Portaria $\mathrm{N}^{\mathrm{o}} 80$ de $1998,{ }^{1}$ que "dispõe sobre o reconhecimento dos mestrados profissionais e da outras providências" (RBPG, 149-150, 2005), estabelece critérios e requisitos para o acompanhamento e avaliação dos mestrados profissionais. Neste sentido o Art. $2^{\circ}$ determina que "Será enquadrado como 'Mestrado Profissionalizante' o curso que atenda aos seguintes requisitos e condições", e menciona os seguintes quatro aspectos: a) estrutura curricular clara, articulando ensino com aplicação profissional e compatível com um tempo de titulação mínimo de um ano; b) quadro docente integrado predominantemente por doutores, com produção intelectual divulgada em veículos reconhecidos e de ampla circulação, podendo uma parcela desse quadro ser constituída "de profissionais de qualificação e experiência inquestionáveis em campo pertinente ao da proposta do curso"; c) condições de trabalho e carga horária compatíveis com o curso, admitido o regime de dedicação parcial; d) exigência de apresentação de trabalho que demonstre domínio do objeto de estudo sobre a forma de dissertação e as outras formas citadas na Portaria $N^{\circ} 47$ anterior.

Deve ser destacado dentre os itens anteriores que já nesta Portaria $N^{\circ} 80$ se estabelece que os docentes devem ter "produção intelectual divulgada em veículos reconhecidos de ampla circulação", o qual não resulta muito coerente com a exigência da aplicabilidade da produção acadêmica dos mestrados profissionais que é sua característica fundamental. $\mathrm{Ou}$ seja, se a aplicabilidade da produção acadêmica é um princípio essencial dos mestrados profissionais é mais importante uma dissertação aplicável que um artigo sem aplicabilidade publicado em veículo de ampla circulação. (Relatório $2^{\circ}$ Encontro dos Mestrados Profissionais, 2012).

Um aspecto adicional também relevante da Portaria $\mathrm{N}^{\mathrm{o}} 80$, é que se menciona que uma parcela dos docentes pode ser constituída de profissionais qualificados e experientes em campo pertinente ao curso, assunto este que a Portaria $N^{\circ} 2$ de $2012^{2}$ regulamenta mais

\footnotetext{
1 Portaria publicada no Diário Oficial de 11/01/99, Seção I, p. 14.

${ }^{2}$ A Portaria N 2 de 2012 "Define, para efeitos de enquadramento nos programas e cursos de pós-graduação, as categorias de docentes dos programas desse nível de ensino".
} 
claramente e flexibiliza a participação dos docentes colaboradores. De fato, as novas diretrizes contidas no Art. $4^{\circ}$ desta recente Portaria, abriram as possibilidades de participação em pesquisa e orientação a profissionais com experiência, ao estabelecer que os Docentes Colaboradores possam participar "de forma sistemática do desenvolvimento de projetos de pesquisa ou atividades de ensino ou extensão e/ou da orientação de estudantes, independentemente do fato de possuírem ou não vínculo com a instituição". (Capes, 2012). Esta norma foi muito bem recebida pelos mestrados profissionais, particularmente da Área Urbano Regional e Demografia, na medida em que permite incorporar profissionais com reconhecida experiência e saber às atividades de docência, pesquisa e orientação, os quais dificilmente poderiam ser vinculados de forma integral as IES porque para eles mesmos não é de interesse deixar suas atividades em institutos de pesquisa ou em empresas de prestígio.

Esta Portaria $N^{\circ} 80$ também estabelece as exigências para as instituições que podem ofertar mestrados profissionais, ressaltando a necessidade da realização de pesquisa e qualificação científica, técnica e ou artística.

Com relação á avaliação dos mestrados profissionais a Portaria estabelece que estes cursos serão avaliados periodicamente utilizando critérios pertinentes ás peculiaridades dos cursos e "dentro do que é previsto pelo sistema de avaliação da pós-graduação patrocinado pela CAPES, em conjunto com todos os demais programas". Menciona-se em outro parágrafo que "a produção técnico-profissional decorrente de atividades de pesquisa, extensão e serviços prestados deverá ser especialmente valorizada" (RBPG, 2005). Esta é a mesma questão que foi comentada anteriormente e considera-se que esta produção técnico-científica deve ser considerada o resultado essencial dos mestrados profissionais e pelo mesmo o critério básico de avaliação do desempenho. Em correlação com esta produção técnicocientífica deve ser avaliada igualmente a sua aplicabilidade, a qual é decorrente da inserção social e/ou da extensão realizada na realidade pesquisada. Ou seja, a aplicabilidade da produção acadêmica está determinada em boa medida pelo grau de inserção social ou profissional que tenha essa produção, a qual pode ser uma dissertação, um projeto urbano ou regional, uma política pública, uma patente, etc. Essa inserção social deve ser realizada pelos orientadores e orientandos na sociedade em geral, em grupos sociais e comunidades locais específicos, em empresas, instituições de poder público, etc., em cujo âmbito a produção no mestrado será aplicada.

A Portaria $\mathrm{N}^{\mathrm{o}} 17$ de 2009, que revogou a Portaria $\mathrm{N}^{\mathrm{o}} 7$ do mesmo ano, estabelece no seu Art. $1^{\circ}$ que a "CAPES regulará a oferta de programas de mestrado profissional mediante chamadas públicas e avaliará os cursos oferecidos, na forma desta Portaria e de sua regulamentação própria". Nessa perspectiva, esta Portaria contém o mais completo conjunto de objetivos e diretrizes sobre os mestrados profissionais, apresentando complementações, ajustes e aspectos adicionais às Portarias precedentes. Destaca-se nesse sentido, como já foi mencionado, a inclusão de uma grande diversidade de modalidades que podem ser apresentadas como trabalho final, além da forma mais convencional de dissertação.

No Art. 2 a Portaria estabelece que "O título de mestre obtido nos cursos de mestrado profissional reconhecidos e avaliados pela CAPES e credenciados pelo Conselho Nacional de Educação - CNE e validados pelo Ministro de Estado da Educação tem validade nacional”. Esta determinação busca deixar clara a validade institucional dos mestrados profissionais no Brasil, os quais, segundo dados apresentados em 2011 no Fórum dos MPs em Pará, tinham atingido um total de 363 cursos.

O Art. 3 da Portaria caracteriza os mestrados profissionais, como aqueles que possibilitam a "capacitação de pessoal para a prática avançada e transformadora de procedimentos e processos aplicados”, por meio de métodos científicos e rigor metodológico; 
incorporação permanente da ciência e das tecnologias, "tendo como foco a gestão, a produção técnico-científica na pesquisa aplicada e a proposição de inovações e aperfeiçoamentos tecnológicos para a solução de problemas específicos" (Capes, 2009).

Os objetivos dos mestrados profissionais são estabelecidos no Art. 4 e reiteram que se trata de capacitar profissionais qualificados para o exercício da prática profissional visando demandas sociais e do mercado do trabalho; transferir conhecimento para a sociedade atendendo demandas específicas e de arranjos produtivos com vistas ao desenvolvimento nacional, regional ou local; promover a integração entre a formação profissional e entidades demandantes de natureza diversas visando melhorar a eficiência das organizações públicas e privadas por meio da solução de problemas. Contribuir para a competitividade e produtividade de empresas e organizações públicas e privadas.

O Parágrafo Único do Art. 5 estabelece que "A oferta de cursos com vistas à formação no Mestrado Profissional terá como ênfase os princípios de aplicabilidade técnica, flexibilidade operacional e organicidade do conhecimento técnico-científico, visando o treinamento de pessoal pela exposição dos alunos aos processos da utilização aplicada dos conhecimentos e o exercício da inovação, visando à valorização da experiência profissional" (Capes, 2012).

Como pode ser observado, as características, objetivos e princípios dos mestrados profissionais estabelecidos com maior detalhe na Portaria $\mathrm{N}^{\circ} 17$ de 2009, reiteram que se trata de cursos orientados para a produção com aplicabilidade na sociedade em geral, a problemas específicos, a empresas e entidades públicas e privadas. Ou seja, a produção acadêmica deve estar orientada para a aplicabilidade, e esta demanda dos alunos e professores uma inserção social e profissional que permita que os resultados sejam aplicados na realidade pesquisada.

A Portaria $\mathrm{N}^{\circ} 17$ de 2007 também estabelece os seguintes requisitos e critérios sobre a Proposta do Programa de Mestrado Profissional nos seguintes termos: estrutura curricular objetiva e coerente com as finalidades do curso, enfatizando no conhecimento atualizado, metodologia pertinente e atuação no campo profissional; interdisciplinaridade com áreas das ciências sociais aplicadas; conciliar a proposta com o perfil dos candidatos; corpo docente equilibrado e integrado por doutores, profissionais e técnicos; normas bem definidas de seleção dos docentes e orientadores; carga horária docente e condições de trabalho compatíveis com as necessidades do curso; trabalhos de conclusão de curso que demonstrem domínio do aluno sobre o objeto de estudo.

Com relação ao corpo docente a Portaria estabelece adicionalmente que deve ser altamente qualificado, conforme demonstrado pela produção intelectual constituída por publicações específicas, produção artística e técnico-científica, ou por reconhecida experiência profissional. Essa qualificação do docente deve ser compatível com a área e a proposta do curso. (Brasil, 2009).

A mudança mais polêmica realizada pela Portaria $N^{\circ} 17$, e que já foi comentada anteriormente, refere-se à ampliação dos formatos nas quais pode ser apresentado o trabalho de conclusão final. O Parágrafo $3^{\circ}$, neste sentido estabelece como modalidades "dissertação, revisão sistemática e aprofundada da literatura, artigo, patente, registros de propriedade intelectual, projetos técnicos, publicações tecnológicas; desenvolvimento de aplicativos, de materiais didáticos e instrucionais e de produtos, processos e técnicas; produção de programas de mídia, editoria, composições, concertos, relatórios finais de pesquisa, softwares, estudos de caso, relatório técnico com regras de sigilo, manual de operação técnica, protocolo experimental ou de aplicação em serviços, proposta de intervenção em procedimentos clínicos 
ou de serviço pertinente, projeto de aplicação ou adequação tecnológica, protótipos para desenvolvimento ou produção de instrumentos, equipamentos e kits, projetos de inovação tecnológica, produção artística; sem prejuízo de outros formatos, de acordo com a natureza da área e a finalidade do curso, desde que previamente propostos e aprovados pela CAPES" (Capes, 2009).

Os objetivos, princípios, características e diretrizes sobre os mestrados profissionais contidos nas Portarias analisadas podem ser resumidos nos seguintes aspectos principais:

- $\quad$ O objetivo essencial dessa modalidade de mestrados é formar profissionais com elementos teóricos, críticos e práticos e a sua produção acadêmica deve estar caracterizada pela a sua aplicabilidade;

- A aplicabilidade da produção acadêmica exige que todas as instâncias do curso de mestrado contribuam para estabelecer articulações para a inserção social em grupos específicos da sociedade civil e com entidades do estado, de forma a garantir a aplicabilidade da produção intelectual no âmbito dos cursos;

- O rigor científico da pesquisa no âmbito dos cursos de mestrado profissional é a forma de garantir o compromisso de que a produção intelectual tenha aplicabilidade e inserção social, com coerência, na realidade pesquisada.

- $\quad$ Este desafio e compromisso exigem uma atualização permanente dos avanços da ciência para atender demandas específicas da sociedade civil e do Estado.

No caso dos mestrados profissionais da área de Planejamento Urbano Regional e Demografia, cabe destacar que os cursos, além da articulação e inserção social para a aplicabilidade da produção intelectual no meio local e regional nos quais estão localizados, é imprescindível que exista uma incorporação das características e dos problemas dessas regiões como objeto de pesquisa e de proposição de soluções particulares a esses âmbitos regionais. afirma:

Neste sentido o comunicado do $2^{\circ}$ Encontro dos Mestrados Profissionais da área,

As características e problemáticas regionais do entorno devem ser determinantes do conteúdo das linhas e projetos de pesquisa, bem como das próprias disciplinas do curso. Desta maneira, a identidade dos mestrados na área deve estar também determinada e orientada pelas características, potencialidades e vulnerabilidades da realidade regional onde o mestrado está inserido. (2012, p.4)

Estas considerações estão orientadas a ressaltar a importância dos mestrados em Desenvolvimento Regional como um instrumento de análise e compreensão da realidade e de formulação e aplicação de propostas de ações e políticas nas regiões nas quais estão localizados, buscando a inserção social para garantir a aplicabilidade.

\subsection{O Compromisso e Desafio das Diversas Instâncias Institucionais relacionadas com os Mestrados Profissionais para a Inserção Social e a Aplicabilidade da Produção Intelectual.}

Cabe reiterar, conforme a legislação vigente, que os mestrados profissionais têm na sua concepção inicial o enorme desafio de gerar conhecimento com aplicabilidade, o qual, ao contrario de que em geral se pensa, implica realizar pesquisa com o necessário rigor científico, de forma a permitir a sua aplicação coerente com as necessidades da realidade pesquisada. Ou seja, para que a produção intelectual e os conhecimentos gerados tenham 
aplicabilidade, necessitam estar fundamentados em uma pesquisa rigorosa da realidade onde vai ser aplicado. É este o principal e motivador desafio dos mestrados profissionais.

É de interesse resgatar o pensamento de Mario Bungue sobre a relação entre ciência e aplicabilidade: "A utilidade da ciência é uma consequência de sua objetividade: sem se propor necessariamente resultados aplicáveis, a pesquisa os proporciona de todas as maneiras" (1992 p.34). É por este motivo que os mestrados profissionais precisam desenvolver pesquisa com rigor científico, pois os resultados terão necessariamente aplicabilidade. Igualmente cabe ressaltar as reflexões que sobre a tecnologia o autor realiza: "A tecnologia não é somente o resultado de aplicar o conhecimento existente sobre os problemas práticos: a tecnologia viva é, essencialmente, o enfoque cientifico dos problemas práticos, ou seja, o tratamento destes problemas sobre um fundo de conhecimento científico" (1992, p.35). Estas contribuições de Bunge são úteis para orientar o desenvolvimento dos mestrados profissionais.

Apresentam-se a seguir algumas reflexões sobre como as IES e as Mantenedoras, a estrutura do programa do mestrado, o corpo docente e o corpo discente podem atuar e contribuir para alcançar o desafio da inserção social e da aplicabilidade da produção intelectual:

\subsubsection{As IES e as Mantenedoras perante a Aplicabilidade e a Inserção Social da Produção Intelectual}

Convém inicialmente mencionar que segundo Marinko (1982, p.9) “A educação pode ser definida, em poucas palavras, como gestão do desenvolvimento das pessoas". Esta concepção simples, mas muito clara, mostra a importância das Instituições de Educação Superior -IES e das próprias Mantenedoras, no caso da educação particular, como aquelas entidades chave na gestão dos mestrados e doutorados e, por tanto, do desenvolvimento da docência, da pesquisa, do conhecimento, dos alunos e evidentemente também dos docentes.

Neste sentido, a Instituição de Estudo Superior - IES da qual faz parte o mestrado e a Mantenedora, devem apoiar a criação e desenvolvimento de um âmbito de pesquisa e docência no qual a aplicabilidade e a inserção social sejam diretrizes permanentes do curso de mestrado profissional. Neste sentido corresponde à IES e à Mantenedora, não somente criar as condições acadêmicas internas necessárias à materialização dessas diretrizes, mas contribuir a estabelecer relações interinstitucionais que facilitem essa articulação para a inserção social junto aos diferentes grupos e agentes da sociedade civil, bem como instituições do Estado.

Para a inserção social junto à sociedade civil, a IES e a Mantenedora devem contribuir a estabelecer contatos com grupos da sociedade, comunidades locais, empresários e demais agentes sociais. Estas instituições encarregadas dos programas podem abrir espaços de articulação utilizando suas relações interinstitucionais a todos os níveis. Desta forma as Mantenedoras não somente cumprem a sua função financeira e administrativa de manter os cursos em funcionamento, mas também servir de apoio à inserção social e à aplicabilidade da produção intelectual.

Na opinião de Ludimar Pegoraro, (2012),

As entidades mantenedoras são instituições, neste caso, criadas com a finalidade específica de desenvolver a educação superior. Elas são o suporte legal para que de fato sejam viabilizadas condições administrativo-financeiras para a efetivação da educação superior. IES e mantenedoras devem constituir, institucionalmente, um único ente jurídico, onde de direito e de fato são viabilizadas estruturas, profissionais, legalidades para que, em um determinado local ou região, sejam efetivadas ações com vistas ao oferecimento da educação superior. 
Relevante opinião do Pegoraro, no sentido de que as IES e suas Mantenedoras são um "único ente jurídico", pois desta forma a aplicabilidade e a inserção social da produção acadêmica é de fato um desafio e compromisso de ambas as instituições, o qual deve ser assumido igualmente como um objetivo essencial compartilhado.

\subsubsection{Estrutura Acadêmica do Programa, Aplicabilidade e Inserção Social}

É sabido que o objetivo essencial da educação é a formação de profissionais com capacidade científica e crítica para a compreensão da sociedade e a capacitação técnica para intervir nela e transformá-la. Ou seja, uma educação para a transformação social buscando uma melhor condição de vida para todos.

É nesta perspectiva que a estrutura acadêmica dos programas deve prever e facilitar a formação teórica e prática, ou seja, fornecer os elementos científicos, críticos e técnicos aos alunos de forma a compreender a realidade e poder atuar sobre ela. Nas palavras de Malinko, "habituar os alunos a ligar mais estreitamente a teoria à prática" (1982, p.15). Esta recomendação também é intrínseca aos mestrados profissionais, pois a exigência da aplicabilidade dos conhecimentos gerados no seu âmbito implica uma relação íntima entre a teoria e a prática.

O Plano Nacional de Pós-Graduação - PNPG - recomenda "a instauração de programas, áreas de concentração e linhas de pesquisa que promovam a convergência de temas e o compartilhamento de problemas, em vez da sua mera agregação ou justaposição". (2010, p.139). É uma recomendação acertada para a estrutura acadêmica dos mestrados, já que no caso dos programas de desenvolvimento regional e urbano essa convergência de problemas se facilita exatamente por que se trata de pesquisa e de formulação de ações em um âmbito territorial, no qual os problemas são abordados de maneira interdisciplinar e compartilhados por diferentes áreas de conhecimento.

\subsubsection{O Perfil do Corpo Docente}

Os projetos de pesquisa dos professores e sua condição de orientadores dos projetos de dissertação dos alunos constituem a base fundamental do funcionamento dos cursos de mestrados profissional, orientados para a aplicabilidade do conhecimento gerado. Corresponde aos professores propor e desenvolver projetos de pesquisa relacionados com problemas e processos de relevância regional, de forma a criar as condições necessárias para que projetos de pesquisa dos alunos compartilhem problemas para sugerir desde perspectivas interdisciplinares ações e políticas aplicáveis.

Segundo o PNPG "O pesquisador pode e deve, além de promover a inovação, participar da inserção do resultado de sua pesquisa no mercado produtivo.”. (2010, p.139). Desta maneira o PNPG incorpora o relevante e cada dia mais vigente paradigma da inovação e também menciona a inserção do resultado da pesquisa no processo produtivo, reforçando desta forma a ideia da aplicabilidade. Ainda com relação aos pesquisadores o PNPG (p.139) assinala a necessidade "da existência de pesquisadores com boa ancoragem disciplinar e formação diversificada", o qual implica ao mesmo tempo uma sólida formação em disciplina específica, mas complementada com elementos diversos de outras áreas de conhecimento. De certa maneira, esta premissa implica a necessidade de uma formação individual interdisciplinar que facilite a compreensão e realização do trabalho multidisciplinar de forma coletiva.

A necessidade da formação interdisciplinar do corpo docente se impõem em função da exigência de um método de análise da realidade social e também em função das finalidades sociais, já que as disciplinas individualmente não conseguem responder adequadamente às 
problemáticas complexas da sociedade. Tais concepções conduzem à afirmação da busca de sínteses conceituais que possam possibilitar a correlação da investigação nas fronteiras das disciplinas e equacionar respostas operacionais coordenadamente planejadas para atender as questões sociais e tecnológicas que são demandadas pela sociedade. (FAZENDA, 1994).

\subsubsection{A Orientação e Produção dos Discentes}

O papel dos discentes é cada dia mais relevante por sua contribuição nos processos coletivos de pesquisa. Alguns estudantes estão chegando ao mestrado com certa experiência no desenvolvimento de projetos, na elaboração de artigos e nos procedimentos de pesquisa. Entretanto e como o aponta o mesmo PNPG, as desigualdades regionais nesta preparação dos estudantes e os meios para apoiar a pesquisa é muito grande. Também é desigual o nível dos estudantes das universidades públicas e das particulares, e ao contrario do que se pensa geralmente, os alunos de condições econômicas menores e que trabalham para pagar seus cursos por que na tem direito a bolsas, encontram nas pequenas universidades privadas uma alternativa para melhorar sua capacitação. As universidades públicas, que são as melhores do país em todas as regiões, são ocupadas pelos filhos das classes sociais ricas, porque são os mais bem preparados e, paradoxalmente, não pagam por essa educação universitária.

Como foi assinalado, compete aos professores com seus projetos consolidar as linhas de pesquisa e orientar aos discentes no desenvolvimento das suas dissertações no âmbito de suas linhas para que exista uma produção intelectual compartilhada, integrada e não dispersa. Entretanto, também convém assinalar que os alunos não podem constituir simplesmente força de trabalho do professor, porque além de ser antidemocrático e pouco ético, pode ser coibida a capacidade inovadora e empreendedora de alunos com essas potencialidades.

\section{Considerações Finais}

Com base na normativa comentada neste artigo e no papel das diferentes instâncias que integram os mestrados profissionais, as considerações finais são as seguintes:

- A formação de profissionais com capacidade científica, crítica e técnica e a produção intelectual com aplicabilidade é o objetivo essencial destes mestrados.

- A inserção social em grupos da sociedade civil, no setor produtivo e em entidades do Estado facilita a aplicabilidade da produção acadêmica.

- O desafio da aplicabilidade e da inserção social exige pesquisa com rigor científico para garantir coerência ás propostas de atuação na realidade.

- A dinâmica socioambiental exige uma atualização permanente dos avanços da ciência para atender demandas específicas da sociedade civil e do Estado;

- As características regionais são determinantes da orientação dos projetos de pesquisa de docentes e discentes.

- As IES e as Mantenedoras devem assumir o compromisso de criar tanto as condições financeiras e de gestão, bem como as das atividades de docência e pesquisa para uma produção intelectual aplicável na realidade regional.

- A Estrutura Acadêmica do mestrado deve permitir e promover, com sua área de concentração e suas linhas e projetos de pesquisa, o exercício da interdisciplinaridade e da abordagem compartilhada de problemas e temas regionais, urbanos e locais. 
- O Corpo Docente é a base permanente dos mestrados e das atividades acadêmicas de pesquisa e docência e devem ter, além da capacitação adequada, os meios, os recursos e a motivação para a realização dessas atividades.

- O Corpo Discente exige uma atenção e dedicação especial dos professores na docência, na pesquisa e na orientação, entretanto deve ficar claro o compromisso dos estudantes na produção intelectual autônoma e comprometida com a realidade social na qual pesquisa e desenvolve a sua dissertação.

\section{Referências Bibliográficas}

Bunge, Mario. La ciencia, su método y su filosofía. 1992. Bogotá.

CAPES - Coordenação de Aperfeiçoamento de Pessoal de Nível Superior. Plano Nacional de Pós-Graduação - PNPG - 2011-2020. Brasília, 2010.

- Portaria $N^{\circ}$ 80, de 16 de dezembro de 1998.

- Portaria Normativa $\mathrm{N}^{\circ}$ 17, de 28 de dezembro de 2009

Coordenação da Área de Planejamento Urbano e Regional /Demografia. Relatório do II Encontro dos Mestrados Profissionais da Área em Goiânia 2012. Brasília, setembro de 2012.

Fazenda, Ivani C. Arantes. Interdisciplinaridade- história, teoria e pesquisa. Campinas: Papirus, 1994.

Malinko,I.I. Et. Al. Metodologia do Ensino das Ciências Sociais. Editorial Progresso. URSS. 1982.

Pegoraro, Ludimar. Instituições de Educação Superior e Entidades Mantenedoras: A Universidade do Contestado. Quaestio: Revista de Estudos em Educação.v.14 n.1. 2012. Universidade de Sorocaba.

Revista Brasileira de Pós-graduação. v. 2, n. 4, p. 147-148, jul. 2005. Portaria no 47 de 17 de outubro de 1995. Brasília DF. 